\title{
Dependence of the proactive behavioral effects of theta-driving septal stimulation on stimulation frequency and behavioral experience: 1. Leverpress experiments
}

\author{
JONATHAN H. WILLIAMS and JEFFREY A. GRAY \\ University of Oxford, Oxford, England
}

\begin{abstract}
We tested whether hippocampal theta has frequency-specific functions related to anxiety. Male rats received chronic implants of septal and subicular electrodes to elicit and record theta. Two to six weeks later, experimental rats received thirty 3-sec trains of theta-driving septal stimulation daily for 10 days; controls were connected to the apparatus, but not stimulated. The results were as follows: $7.7-\mathrm{Hz}$ or $8.3-\mathrm{Hz}$ theta driving before acquisition of a fixed-ratio 5 (FR5) barpress response increased its resistance to extinction subsequently (Experiment 1 ). In contrast, 7.5-Hz theta driving before acquisition of the FR5 response facilitated its later extinction (Experiment 2). Finally, 8.3-Hz theta driving after acquisition of the FR5 response also facilitated its extinction (Experiment 3 ). Thus, theta-driving stimulation (1) has nonassociative behavioral effects, which (2) are exquisitely frequency specific (Experiments 1-2) and (3) are modified by associative processes during acquisition of an appetitive response (Experiment 3). Theta is involved in producing anxiety, but not via spatial, motor, or memorial mechanisms.
\end{abstract}

Theta is a large-amplitude quasi-sinusoidal electrical rhythm generated in the hippocampus and dentate gyrus (see review by Bland, 1986). Theta occurs in many species, including primates (Stewart \& Fox, 1991). Despite intensive study over 40 years (Green \& Arduini, 1954), the functions of theta are uncertain.

Many workers have studied correlations between theta and behavior (e.g., Buszaki, Rappelsberger, \& Kellenyi, 1985; Leung, 1984; Morris \& Hagan, 1983; Vanderwolf, 1971; Whishaw \& Vanderwolf, 1973). Their results suggested that theta is merely an epiphenomenon of motor activity. The alternative hypothesis, that theta modulates behavior and the brain, has received little attention.

Testing the hypothesis that theta modulates behavior requires analysis of the behavioral effects of manipulating theta. Probably the most selective method of manipulating theta is electrical stimulation of the medial septum. Such stimulation can induce theta at predetermined times and frequencies (Gray \& Ball, 1970; James, McNaughton, Rawlins, Feldon, \& Gray, 1977; Kramis \& Vanderwolf, 1980; Stumpf, 1965). Behavioral studies have shown that theta-inducing septal stimulation (theta driving) can alter appetitive alley running (Gray, 1972), leverpressing (Glazer, 1974b; Holt \& Gray, 1983b, 1985), T-maze discrimination (Deupree, Coppock, \& Willer, 1982), and avoidance

This research was supported by a Medical Research Council Studentship to J.H.W. Correspondence concerning this article should be addressed to J. H. Williams, Department of Experimental Psychology, South Park Rd., Oxford OX1 3UD, England. J.A.G. is now at The Institute of Psychiatry, De Crespigny Park, Denmark Hill, London SE5 $8 \mathrm{AF}$, England. learning (Landfield, 1977; Wetzel, Ott, \& Matthies, 1977). This small body of evidence indicates that theta may be more than an epiphenomenon of motor activity, and that it may modulate behavior.

Interpreting the behavioral effects of theta-driving stimulation is not straightforward, because they may result not from driving theta, but from other neurophysiological effects. For example, theta-frequency stimulation that does not drive theta can modulate noradrenergic function (Graham-Jones, Holt, Gray, \& Fillenz, 1985) and long term potentiation (LTP) (Larson \& Lynch, 1986; Larson, Wang, \& Lynch, 1986; Larson, Xiao, \& Lynch, 1993; Lynch, Kessler, Arai, \& Larson, 1990; Staubli \& Lynch, 1987). To establish that theta production is critical, it would be necessary to show that eliminating the thetadriving effect of septal stimulation, while preserving its other neurophysiological actions, prevented its behavioral effects. However, existing methods of achieving this elimination (e.g., fimbria-fornix lesions; Rawlins, Feldon, \& Gray, 1980b) themselves affect behavior (see, e.g., Rawlins, Feldon, \& Gray, 1980a; Williams, Gray, Sinden, Buckland, \& Rawlins, 1990). An alternative approach is to induce theta by means other than septal stimulation. This has been done both pharmacologically (Bohus, Urban, van Griedanus, \& de Wied, 1978; de Wied, Bohus, van Ree, \& Urban, 1978; Glazer, 1972; Urban \& de Wied, 1978 ) and by instrumental reinforcement of theta production (Glazer, 1974a). However, neither of these methods can alter theta in isolation. The present studies used a different strategy, based on the view that the effects of theta in modulating the brain and behavior are frequency specific. In this case, the behavioral effects of theta-driving 
septal stimulation should also be frequency specific. Moreover, it is highly unlikely that neural systems unconnected with theta would show similar frequency specificities. To date, no published reports have compared the behavioral effects of theta-driving septal stimulation at different frequencies.

Several hypotheses have proposed that theta is involved in memory processes and spatial mapping (e.g., Landfield, 1977; Larson et al., 1986; O'Keefe, 1993; O'Keefe \& Nadel, 1978; Vertes, 1986). These hypotheses do not predict frequency-specific roles for theta. In contrast, Gray's $(1970,1982)$ frustration-anxiety hypothesis does predict such frequency specificities. This hypothesis views $7.7-\mathrm{Hz}$ theta as a transition point between a low-frequency band associated with anxiety and behavioral inhibition and a high-frequency band associated with approach behavior. In the present experiments, we tested the frustration-anxiety hypothesis of theta function by analyzing the effects of theta-driving septal stimulation at frequencies centered on $7.7 \mathrm{~Hz}$ on a behavioral measure of frustration. To simplify interpretation of the results, we minimized memorial processes and spatial mapping by applying stimulation before beginning operant training (so there were no memories to be altered) and by studying a barpress response (which requires minimal spatial processing).

Gray's (1982) frustration-anxiety hypothesis has already been tested in several theta-driving studies. In some, the behavioral effects of theta driving were analyzed in Glazer's (1974b) fixed-ratio 5 (FR5) barpress paradigm (Holt, 1982; Holt \& Gray, 1983b, 1985). In these studies, it was assumed that this paradigm is functionally equivalent to a continuous reinforcement (CRF) schedule in the straight alley. Recently, however, we have found that the FR5 response may be functionally equivalent to an alley partial reinforcement (PRF) schedule (Williams et al., 1990). In Experiment 3 of the present report, we explore the profound consequences of this changed understanding of the nature of the FR5 schedule for interpreting the effects of theta driving upon resistance to extinction of the FR5 response (and see Williams, Gray, Snape, \& Holt, 1989).

\section{GENERAL METHOD}

\section{Subjects}

All subjects were male Sprague-Dawley rats. The rats were housed singly in wire mesh cages after operation. They were allowed access to water ad lib throughout each experiment. Food was available ad lib until 2-3 weeks after surgery. We then phased in a food deprivation schedule, consisting of $12-15 \mathrm{~g}$ of chow provided at least $1 \mathrm{~h}$ after any stimulation or behavioral procedures. The rats were maintained on a 12:12-h light:dark cycle with lights on at 0830. All stimulation and behavioral procedures took place between 0900 and 1800 .

\section{Surgery}

All rats received chronic implants of subicular recording electrodes and $40^{\circ}$-angled septal stimulating electrodes as described previously (see James et al., 1977; McNaughton, Azmitia, Williams, Buchan, \& Gray, 1980). Bipolar twisted-wire electrodes were made from two insulated stainless steel wires $(0.1-\mathrm{mm}$ o.d.; Diamel 316L-34\% Elong., California Fine Wire Co.). The tip separations were $1.5 \mathrm{~mm}$ for the septal stimulating electrodes and $2.0 \mathrm{~mm}$ for the subicular recording electrodes. The subicular electrodes were implanted at coordinates relative to bregma: AP $-6.0 \mathrm{~mm}, \mathrm{~L}$ $+0.5 \mathrm{~mm}, \mathrm{~V}-5.0 \mathrm{~mm}$. The septal electrodes were implanted at coordinates measured relative to bregma at a lateral angle of $40^{\circ}$ to the median plane: AP $+0.5 \mathrm{~mm}, \mathrm{~L}-3.7 \mathrm{~mm}, \mathrm{~V}-5.7 \mathrm{~mm}$. The tips of the stimulating electrode thus straddled the medial septum. The electrodes were fixed to the skull with dental cement anchored to bone screws. An uninsulated stainless steel wire wound around the bone screws served as an earth. The electrode and earth wires were brought to a plastic socket (Amphenol), which was then fixed to the skull with dental cement. The rats recovered from surgery for 2-6 weeks before stimulation procedures began.

\section{Theta-Driving Stimulation}

The theta-driving stimulation and EEG recording methods have been described in detail elsewhere (Holt, 1982; James et al., 1977; Williams, 1988). An optically isolated square-wave pulse generator (Farnell Instruments) provided bipolar theta-driving septal stimulation. The pulse width was $0.5 \mathrm{msec}$ and the interpulse interval varied from 108 to $145 \mathrm{msec}$ in different experiments, as detailed below. A multichannel polygraph (Grass Corporation 79D with 7P5B preamplifiers) amplified the theta response from the subicular recording electrodes, which was then monitored on a dual-beam oscilloscope (Tektronix 502A) triggered by the pulse generator.

Stimulation and recording procedures used three open-topped Perspex chambers $(24 \times 24 \mathrm{~cm}$ floor $)$ in a dimly lit room. Each chamber contained a counterbalanced shielded cable, which allowed the rat to move freely when connected. In each session, 2 rats received stimulation and a 3 rd was an unstimulated control. Stimulation sessions always contained animals allocated to different experimental groups (see below), and the rats from each group were balanced as far as possible over the three stimulation chambers.

All rats were tested briefly to determine the threshold current required for septal stimulation to drive theta, as described previously (Holt \& Gray, 1983b; James et al., 1977). In each study, the experimental groups were balanced for theta-driving threshold currents determined in these test sessions. Subsequently, all animals were run in 8-10 daily stimulation sessions as detailed in each experiment. Animals allocated to stimulated groups received a total of $90 \mathrm{sec}$ of stimulation per session. Stimulation was given in 3-sec trains on a fixed-time 16 -sec schedule at various frequencies as detailed in each experiment; control rats were connected to the apparatus throughout this 10 -min period but received no stimulation. Stimulation frequencies were calibrated in Experiments 1 and 3 against two independent sources $(50-\mathrm{Hz}$ mains signal; Levell TG2000DM oscillator) and were checked post hoc by analysis of paper EEG records in all experiments.

\section{Behavioral Procedures}

The operant chambers and behavioral procedures have been detailed elsewhere (Williams et al., 1990).

Four operant chambers were used, each containing a retractable lever, pellet hopper, and houselight. Each rat was allocated to a single chamber for all behavioral testing. The rats were first trained for three daily sessions on a free-operant leverpress schedule. They were then shaped to a discrete-trial FR5 response over seven daily sessions. In each discrete trial, completion of the FR requirement caused pellet delivery, lever withdrawal, and switching off of the houselight. The number of trials was progressively reduced, and the intertrial interval increased, during shaping to approximate the definitive acquisition schedule.

FR5 acquisition training and extinction testing sessions were run daily for 12-13 and 10 days respectively, as detailed in each experiment. Each session consisted of four discrete trials with an 
intertrial interval of $1 \mathrm{~min}$ in darkness. Extinction was identical to acquisition, except that the pellet feeder was disconnected. During extinction, if no leverpress occurred before a preset extinction criterion $(300 \mathrm{sec})$, the current trial and session terminated and 300$\mathrm{sec}$ latencies were allocated for all the remaining responses in that session. An on-line computer (NOVA 4, Data General) programmed in the ACT-N language controlled stimulus presentations and measured leverpress latencies to the nearest $20 \mathrm{msec}$.

\section{Statistical Analyses}

The latency data were cumulated over the four trials in each session and divided into three components: $L 1$, the latency to the first press; L2, the time taken for the second and third presses; and L3, the time taken for the fourth and fifth presses. Since the results for L2 and L3 were very similar (for details, see Williams, 1988), they were summed; only the $\mathrm{L} 1$ and the combined $\mathrm{L}(2+3)$ scores are reported here. Where $\mathrm{Ll}$ and $\mathrm{L}(2+3)$ scores showed very similar results, these too were summed to give a total FR5 latency. All data were $\log$ transformed to improve their homoscedasticity (see Williams, 1988), and subjected to analyses of variance (ANOVAs) with repeated measures and polynomial analyses of trends over days. Post hoc $t$ tests were based on the appropriate ANOVA error terms.

\section{EXPERIMENT 1}

Gray's (1982) frustration-anxiety hypothesis predicts that $7.7-\mathrm{Hz}$ and $8.3-\mathrm{Hz}$ theta have different functions, with $7.7-\mathrm{Hz}$ theta related to the processing of anxiogenic stimuli but $8.3-\mathrm{Hz}$ theta related to approach. No previous studies have directly compared the behavioral effects of $8.3-\mathrm{Hz}$ and $7.7-\mathrm{Hz}$ theta driving (Williams et al., 1989). Experiment 1 compared the effects of $7.7-\mathrm{Hz}$ and $8.3-\mathrm{Hz}$ theta driving, applied before acquisition, on extinction of an appetitive FR5 response (Holt \& Gray, 1983b).

\section{Method}

Experiment 1 was part of a larger one, in which some rats were stimulated after FR5 acquisition training, as described below (Experiment 3 ). In this section, we will detail only differences from the General Method section. Here we report data from 27 animals: (1) 9 unstimulated controls run in stimulation sessions before FR5 acquisition (U-PRE), (2) 9 animals stimulated at $8.3 \mathrm{~Hz}$ before FR5 acquisition (8.3-PRE), and (3) 9 animals stimulated at $7.7 \mathrm{~Hz}$ before FR5 acquisition (7.7-PRE).

The rats weighed $360-500 \mathrm{~g}$ at operation. They received chronic implants of septal stimulating and subicular recording electrodes. Following recovery and test stimulation, they were run in 10 daily stimulation sessions and were then shaped to the FRS response over 10 daily sessions. They then received 13 days of FR5 acquisition training and 10 days of extinction testing. The latency data were analyzed in a two-factor ANOVA: group (unstimulated, $7.7 \mathrm{~Hz}$ stimulated, or $8.3 \mathrm{~Hz}$ stimulated) $\times$ days (of acquisition training or extinction testing).

\section{Results}

Theta-driving measures. The mean theta-driving thresholds of the stimulated and control groups in the test stimulation session were as follows: U-PRE, $168 \mu \mathrm{A}$; 7.7-PRE, $137 \mu \mathrm{A} ; 8.3-\mathrm{PRE}, 129 \mu \mathrm{A}$. These values did not differ significantly (see Experiment 3 ). The mean frequencies of driven theta for the 7.7-PRE and 8.3-PRE groups were $7.71 \pm 0.03 \mathrm{~Hz}$ and $8.28 \pm 0.15 \mathrm{~Hz}$, respectively. Examples of driven theta are shown in Figure 1.

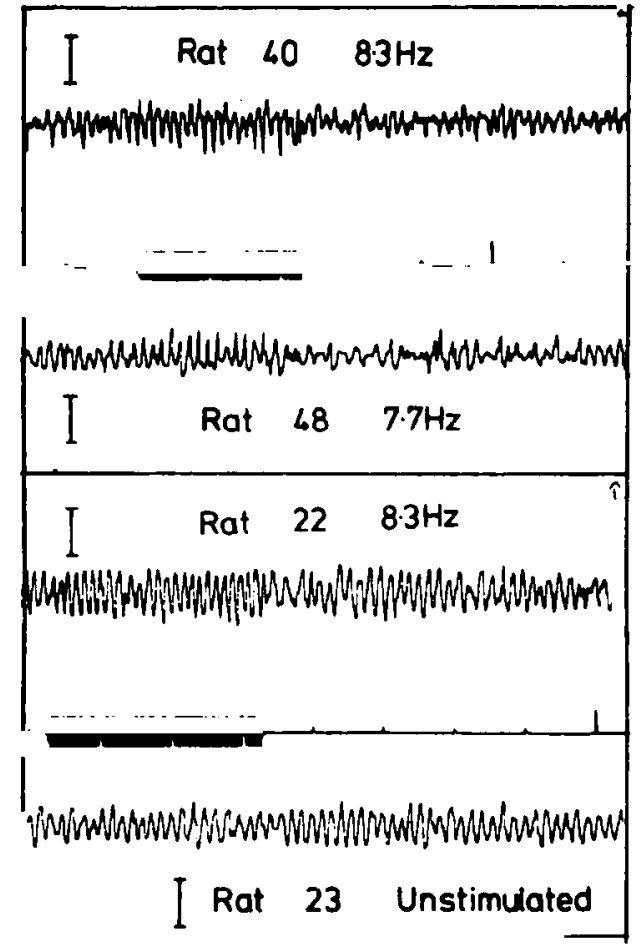

Figure 1. EEG records showing examples of theta driving by $8.3-$ or $7.7-\mathrm{Hz}$ septal stimulation using 3-sec stimulation trains on fixedtime 16-sec schedules. The vertical calibration bars represent $500 \mu \mathrm{V}$. The time scales on the central traces show seconds. Stimulation occurred during the periods marked by solid bars on the central traces, at the frequencies shown for each rat. Unstimulated controls (e.g., Rat 23) were connected to the apparatus in each session, but received no stimulation.

Acquisition. All groups tended to asymptotic FR5 responding during acquisition, as indicated by significant linear $[F(1,289)=14.20, p<.001]$ and quadratic $[F(1,289)=6.39, p<.01]$ trends over days. The stimulated and control groups did not differ during acquisition (all $F \mathrm{~s}<1$; not shown).

Extinction. The $7.7-\mathrm{Hz}$ group was more resistant to extinction of the initial leverpress than the other groups (data not shown). An ANOVA of the L1 scores showed significant differences between the linear trends in the groups $\times$ days interaction $[F(2,235)=6.14, p<$ $.01]$.

Both the $7.7-\mathrm{Hz}$ and $8.3-\mathrm{Hz}$ stimulated groups were more resistant than the unstimulated controls to extinction of the later response components (Figure 2). An ANOVA of the $L(2+3)$ scores showed significant differences between the linear trends in the groups $\times$ days interaction $[F(2,235)=4.79, p<.01]$. Post hoc comparisons between the linear coefficients confirmed that both the stimulated groups were significantly resistant to extinction compared to the controls $[7.7 \mathrm{~Hz}$ vs. control, $t(235)=3.98, p<.001 ; 8.3 \mathrm{~Hz}$ vs. control, $t(235)=2.24$, $p<.05]$. Resistance to extinction in the $7.7-\mathrm{Hz}$ stimulated group was somewhat greater than in the $8.3-\mathrm{Hz}$ group, an 


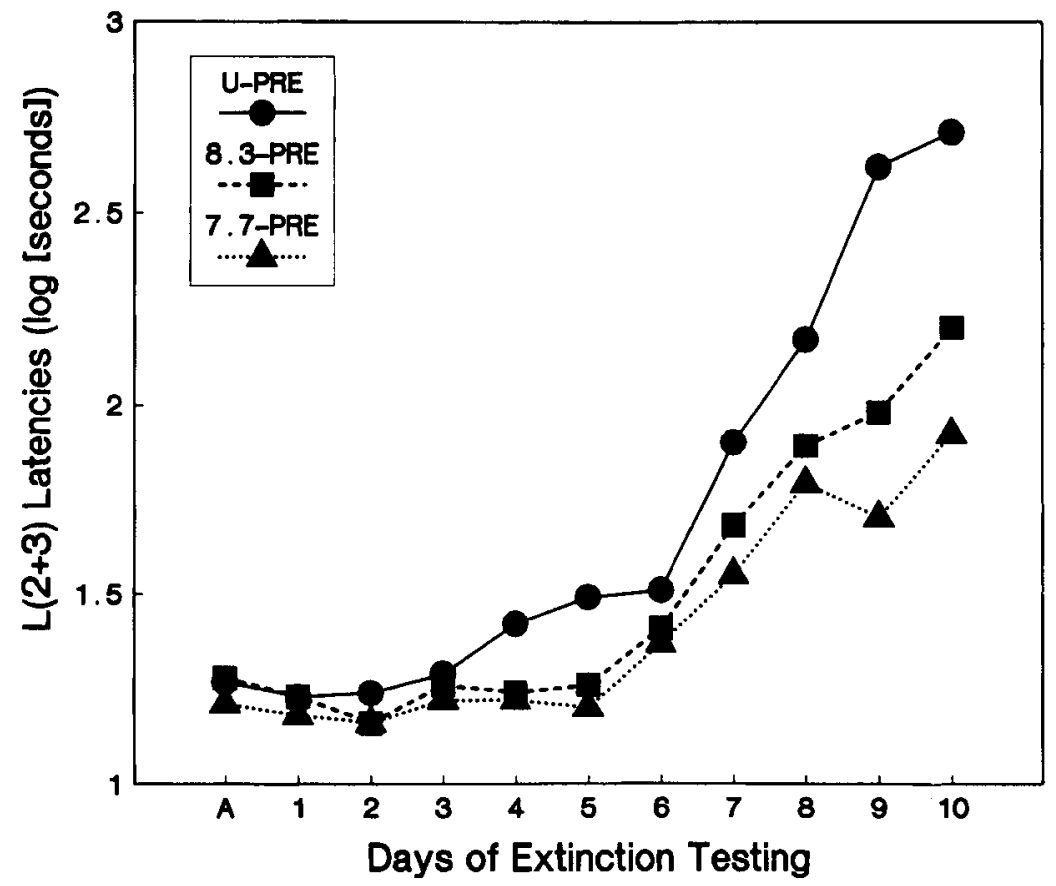

Figure 2. The $L(2+3)$ scores of the 7.7-Hz (7.7-PRE) and 8.3-Hz stimulated (8.3-PRE) and unstimulated control (U-PRE) groups (ordinate) on the last day of acquisition and the 10 days of extinction (abscissa) in Experiment 1. The values shown are the means of logtransformed data.

effect that was not, however, significant $[t(235)=1.74$, $.10>p>.05]$.

\section{Discussion}

Both $7.7-\mathrm{Hz}$ and $8.3-\mathrm{Hz}$ theta-driving stimulation applied before FR 5 acquisition increased subsequent resistance to extinction of the FR5 leverpress response. These findings agree with earlier reports (which each tested one frequency) (Glazer, 1974b; Gray, 1972; Holt \& Gray, 1983b). Moreover, as observed by Holt and Gray (1983b), the proactive effects of theta-driving stimulation were more marked in the later components of the FR5 response and in the later stages of extinction. Although Holt and Gray (1983b) reported their stimulation frequency as $7.7 \mathrm{~Hz}$, it was in fact $8.3 \mathrm{~Hz}$ (see Williams et al., 1989). Thus the present finding that $7.7-\mathrm{Hz}$ theta driving proactively increased resistance to extinction of the FR5 response is the first report of this effect at this stimulation frequency. This is in line with the particular relationship of $7.7-\mathrm{Hz}$ theta to nonreward (Gray \& Ball, 1970 ) and the sensitivity of this frequency to the action of anxiolytic drugs (McNaughton et al., 1977).

Neither $7.7-\mathrm{Hz}$ nor $8.3-\mathrm{Hz}$ stimulation theta driving affected FR5 acquisition performance in the present experiment. This eliminates the possibility that the effects of theta driving on resistance to extinction might be secondary to an alteration in the baseline behavior subjected to extinction. However, as shown in Experiment 3 below, it still remains possible that the effects of theta driving on extinction depend on changes in the learning processes that are engaged by acquisition.

The increase in resistance to extinction after $7.7-\mathrm{Hz}$ stimulation was clear cut and (nonsignificantly) greater than after $8.3-\mathrm{Hz}$ stimulation. However, the frustrationanxiety hypothesis of theta function (Gray, 1970, 1982) does not predict that stimulation at $7.7 \mathrm{~Hz}$ or $8.3 \mathrm{~Hz}$ should have the same effects. This hypothesis relates theta frequencies above $7.7 \mathrm{~Hz}$ to approach behavior rather than to frustration or anxiety. It is possible, however, that the transition to a functionally distinct frequency occurs above $8.3 \mathrm{~Hz}$. In the experiments on the effects of anxiolytic drugs on thresholds for septal driving of hippocampal theta, in which selective effects were obtained at $7.7 \mathrm{~Hz}$, the next highest frequency studied was $9.1 \mathrm{~Hz}$ (McNaughton et al., 1977).

\section{EXPERIMENT 2}

Gray's $(1970,1982)$ frustration-anxiety hypothesis of theta function treats $7.7 \mathrm{~Hz}$ as a transition point between a low-frequency band of theta associated with anxiety and behavioral inhibition and a high-frequency band related to approach behavior. Experiment 2 tested whether the behavioral effects of stimulation at a lower frequency$7.5 \mathrm{~Hz}$ - would resemble those obtained at $7.7 \mathrm{~Hz}$.

Several previous lines of evidence suggest that lower frequencies of theta may have functional properties different from those of $7.7 \mathrm{~Hz}$. First, disruption of seroton- 
ergic function or manipulations of adrenal corticosteroids reduce the threshold for septal elicitation of theta at about $6.9 \mathrm{~Hz}$ (Azmitia, McNaughton, Tsaltas, Fillenz, \& Gray, 1985; McNaughton et al., 1980). In contrast, $7.7-\mathrm{Hz}$ theta showed special sensitivity to anxiolytic drugs and disruption of noradrenergic function (Gray, McNaughton, James, \& Kelly, 1975; McNaughton et al., 1977). Second, de Wied and his colleagues (Bohus et al., 1978; de Wied et al., 1978; Urban \& de Wied, 1978) analyzed the effects of neuropeptide manipulations on the power spectrum of hippocampal theta frequencies during paradoxical sleep (PS) and on avoidance behavior. They found that $\mathrm{ACTH}_{4-10}$ and vasopressin enhanced PS theta power at $7.5-8.0 \mathrm{~Hz}$ and improved avoidance behavior. In contrast, oxytocin and antivasopressin antiserum enhanced PS theta power at about $7.0 \mathrm{~Hz}$ and impaired avoidance. These correlational results suggested that the behavioral functions of theta reverse over the frequency range 7-8 Hz. Third, Holt (1982, Experiments 6.1 and 6.2; and see Williams et al., 1989) studied the proactive effects on FR5 responding of prior theta-driving stimulation at several frequencies. Theta driving at 4.5 , 11.0 , or $17.0 \mathrm{~Hz}$ increased resistance to extinction, but theta driving at $7.5 \mathrm{~Hz}$ (which Holt intended to be $6.9 \mathrm{~Hz}$; see Williams et al., 1989) facilitated extinction. In Experiment 2 , we set out to replicate this effect of theta driving at $7.5 \mathrm{~Hz}$.

Holt (1982, Experiments 6.1 and 6.2) observed no increase in resistance to extinction in $8.3-\mathrm{Hz}$ stimulated rats in studies which included $7.5-\mathrm{Hz}$ stimulated animals. These were Holt's only experiments which showed no behavioral effect of $8.3-\mathrm{Hz}$ stimulation. The present study included a group stimulated at $8.3 \mathrm{~Hz}$ (as well as groups stimulated at 6.8 and $9.3 \mathrm{~Hz}$ ). This allowed us to test the possibility that, as in Holt's work, $8.3-\mathrm{Hz}$ stimulated rats would not show increased resistance to extinction in a study including a $7.5-\mathrm{Hz}$ stimulated group.

\section{Method}

Fifty male rats, weighing $360-480 \mathrm{~g}$, received chronic implants of septal stimulating and subicular recording elect rodes (see General Method section).

Rats with good theta driving were semirandomly allocated to four treatment groups ( $n=10$ each) balanced for theta-driving threshold currents. These four groups were then randomly allocated to receive theta-driving stimulation at $6.8,7.5,8.3$, or $9.3 \mathrm{~Hz}$. The remaining rats, which had faulty recording electrode connections $(9 / 10)$ or poor theta driving $(1 / 10)$, were allocated to be unstimulated controls. Eight experimental stimulation sessions were run on consecutive days.

Behavioral procedures began on the day after theta-driving stimulation sessions. The rats were shaped to the FR5 response over seven daily sessions. FR5 acquisition training and extinction testing sessions were run for 12 and 10 days respectively. Six rats did not learn the FR 5 barpress response and were dropped from the experiment. Forty-four rats completed the experiment: 9 unstimulated controls, 8 stimulated at $6.8 \mathrm{~Hz}, 9$ at $7.5 \mathrm{~Hz}, 9$ at $8.3 \mathrm{~Hz}$, and 9 at $9.3 \mathrm{~Hz}$

The log-transformed latency data were analyzed in ANOVAs with a factorial design of (frequency within stimulation) $\times$ days.

\section{Results}

Theta driving. The mean theta-driving stimulation currents for each experimental group were as follows: "6.8 Hz," $104 \mu \mathrm{A}$; "7.5 Hz," $96 \mu \mathrm{A}$; "8.3 Hz," $108 \mu \mathrm{A}$; " $9.3 \mathrm{~Hz}$," $122 \mu \mathrm{A}$. These values did not differ significantly between groups $(F<1)$. The mean frequencies of driven theta $( \pm S D)$ for each experimental group were as follows: "6.8 Hz," $6.82 \pm 0.07 \mathrm{~Hz}$; "7.5 Hz," 7.52

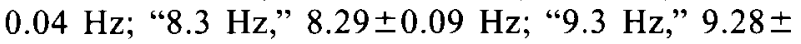
$0.03 \mathrm{~Hz}$. Figure 3 shows examples of driven theta.

Acquisition. All groups acquired the FR5 response, as evidenced by a significant overall linear trend of the total FR5 latencies over days $[F(1,429)=174.5, p<$ $.001]$. The various stimulated and control groups did not differ in this respect $(F=0.77$; n.s.; data not shown).

Extinction. The $7.5-\mathrm{Hz}$ stimulated group showed faster extinction of FR5 responding than did groups stimulated at other frequencies (Figure 4). An ANOVA showed significant differences between the linear trends in the (frequency within stimulation) $\times$ days interaction $[F(3,390)=6.12, p<.001]$. Post hoc comparisons of the slope coefficients indicated that the $7.5-\mathrm{Hz}$ stimulated group extinguished significantly more quickly than every

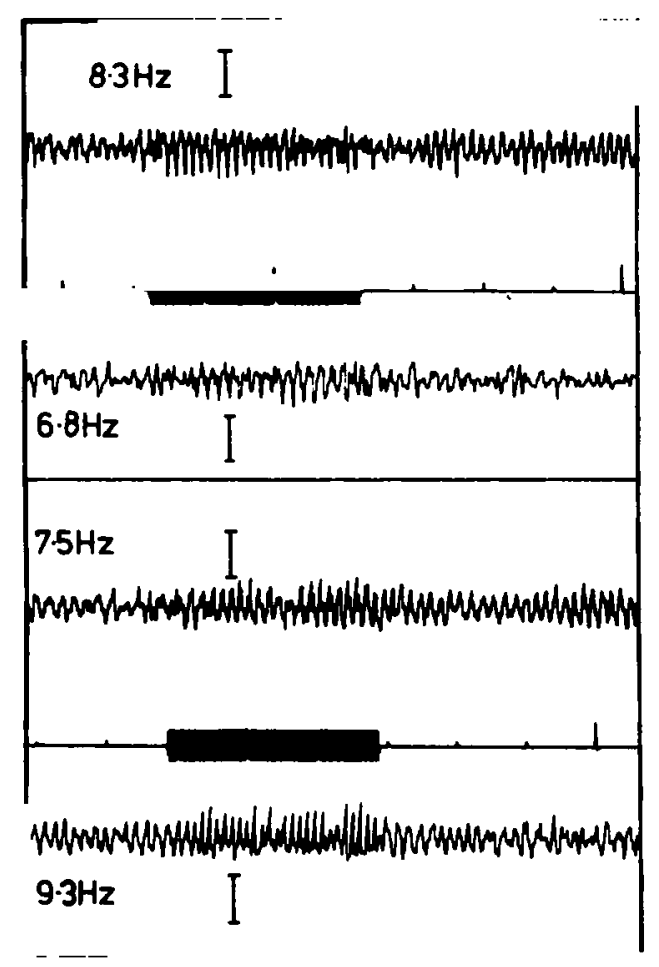

Figure 3. EEG records showing examples of theta driving by 6.8-, 7.5-, 8.3-, or 9.3-Hz septal stimulation using 3-sec stimulation trains on fixed-time 16-sec schedules. The vertical calibration bars represent $500 \mu \mathrm{V}$. The time scales on the central traces show seconds. Stimulation occurred during the periods marked by solid bars on the central traces, at the frequencies shown for each rat. Unstimulated controls were connected to the apparatus in each session, but received no stimulation. 


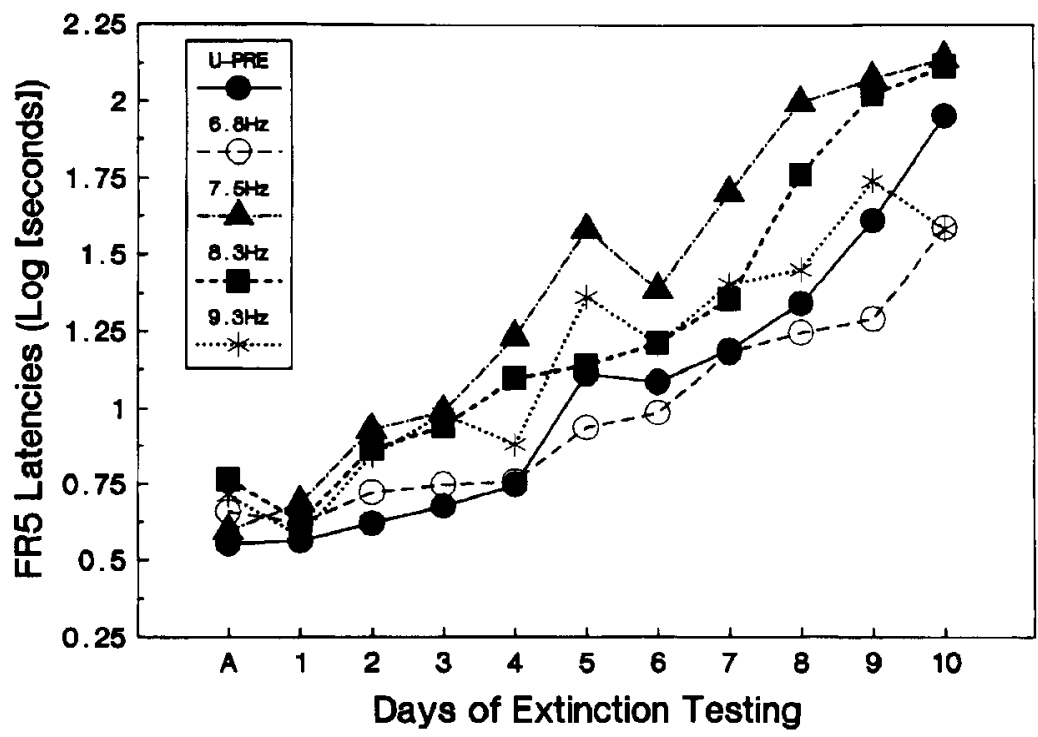

Figure 4. The total FR5 latencies of the 6.8-, 7.5-,8.3-, and 9.3-Hz stimulated groups and unstimulated controls (ordinate) on the last day of FR5 acquisition training and the 10 days of extinction testing (abscissa) in Experiment 2. The values shown are the means of log-transformed data.

other group, and none of the other groups differed significantly from each other (Figure 4; Table 1, Total FR5). This effect was most pronounced in the $\mathrm{L}(2+3)$ component $[F(3,390)=4.42, p<.01)($ Table $1, \mathrm{~L}[2+3])$.

\section{Discussion}

7.5- $\mathrm{Hz}$ theta driving proactively decreased the resistance to extinction of the FR5 response. This confirms
Holt's (1982, Experiments 6.1 and 6.2; see Williams et al., 1989) findings with this frequency. This result was not secondary to altered acquisition performance, which $7.5 \mathrm{~Hz}$ stimulation did not change. The direction of the change in resistance to extinction produced by $7.5-\mathrm{Hz}$ stimulation was, therefore, opposite to that observed after both 8.3- and 7.7- $\mathrm{Hz}$ stimulation (Holt \& Gray, 1983b; Experiment 1 of the present report). The striking contrast

Table 1

Linear Trend Coefficients of Different Frequency Groups During Extinction of the FR5 Response

\begin{tabular}{|c|c|c|c|c|c|c|}
\hline & \multicolumn{5}{|c|}{ Group } & \multirow[b]{2}{*}{ ESE } \\
\hline & Unstimulated & $6.8 \mathrm{~Hz}$ & $7.5 \mathrm{~Hz}$ & $8.3 \mathrm{~Hz}$ & $9.3 \mathrm{~Hz}$ & \\
\hline \multicolumn{7}{|c|}{ Total FR5 Latencies } \\
\hline $\begin{array}{l}\text { Coefficient } \\
\text { Unstimulated } \\
6.8 \mathrm{~Hz} \\
7.5 \mathrm{~Hz} \\
8.3 \mathrm{~Hz}\end{array}$ & 17.4 & $\begin{array}{r}-1.0 \\
\text { n.s. }\end{array}$ & $\begin{array}{c}3.6 \\
* \\
*\end{array}$ & $\begin{array}{l}-0.3 \\
\text { n.s. } \\
\text { n.s. } \\
*\end{array}$ & $\begin{array}{c}-2.4 \\
\text { n.s. } \\
\text { n.s. } \\
\dagger \\
\text { n.s. }\end{array}$ & $1.31-1.39$ \\
\hline \multicolumn{7}{|c|}{$\mathrm{L}(2+3)$ Latencies } \\
\hline $\begin{array}{l}\text { Coefficient } \\
\text { Unstimulated } \\
6.8 \mathrm{~Hz} \\
7.5 \mathrm{~Hz} \\
8.3 \mathrm{~Hz}\end{array}$ & 15.3 & $\begin{array}{r}-1.5 \\
\text { n.s. }\end{array}$ & $\begin{array}{c}4.7 \\
* \\
+\end{array}$ & $\begin{array}{l}-0.5 \\
\text { n.s. } \\
\text { n.s. } \\
\text { * }\end{array}$ & $\begin{array}{c}-2.9 \\
\text { n.s. } \\
\text { n.s. } \\
\dagger \\
\text { n.s. }\end{array}$ & $1.47-1.56$ \\
\hline
\end{tabular}

Note-The table shows the slope coefficients of the linear trends of the response latencies over days for the different stimulated and control groups, and a matrix of significance tests for comparisons between each group. ESE, effective standard error. The slope coefficient for the unstimulated control group is the real slope of the linear regression through the daily mean scores of the group $(\times 100)$. The slope coefficients for the stimulated groups are expressed as deviations from the coefficient of the unstimulated group, so that the real coefficient for a stimulated group is the algebraic sum of its coefficient with the coefficient of the unstimulated group. ${ }^{*} p<$ .05 . $\dagger p<.01$. 
between the effects of 7.7- and 7.5-Hz stimulation strongly supports the view that theta-driving septal stimulation alters behavior via its effects on theta. It is highly unlikely that lowering the stimulation frequency from 7.7 to $7.5 \mathrm{~Hz}$ would have opposite effects on behavior by differentially activating neural systems uninvolved in theta generation.

A firm conclusion that $7.5-\mathrm{Hz}$ stimulation has opposite effects from those of $7.7-$ or $8.3-\mathrm{Hz}$ stimulation would, however, require the observation of opposite directions of change in resistance to extinction in the same experiment. The design of Experiment 2 allowed such observations to be made, but there was no effect of $8.3-\mathrm{Hz}$ stimulation on resistance to extinction in this experiment. Holt (1982) similarly failed to observe increased resistance to extinction of the FR5 response after $8.3-\mathrm{Hz}$ stimulation in two experiments which, like the present study, included a group stimulated at $7.5 \mathrm{~Hz}$. This pattern of results is, therefore, robust. In fact, reviewing our work, eight out of nine of the studies with $8.3-\mathrm{Hz}$ stimulated groups alone found increased resistance to extinction, but four out of four studies with both 8.3 - and $7.5-\mathrm{Hz}$ stimulated groups found no increase in resistance to extinction in the $8.3-\mathrm{Hz}$ stimulated animals (Holt, 1982; Williams, 1988). These contrasting results (8:1 vs. $0: 4$ ) differ significantly (Fisher exact test: $p=.008$ ), and this requires further investigation. It appears that 7.5- $\mathrm{Hz}$ stimulated animals interact with those stimulated at $8.3 \mathrm{~Hz}$ in some way. Since the animals were housed singly and were tested in isolated chambers, the most likely route for such an interaction may be pheromonal signals left in the apparatus. This hypothesis has yet to be tested, but it poses clear problems for the simultaneous study of groups stimulated at the two frequencies of interest. Thus determination of the reliability of the difference between the effects of stimulation at $7.5 \mathrm{~Hz}$ and either 7.7 or $8.3 \mathrm{~Hz}$ requires replication in separate studies at each frequency of stimulation. Such a replication (but using a running response rather than leverpressing) is reported in a companion paper (Snape, Grigoryan, Sinden, \& Gray, 1996; see General Discussion).

No changes in resistance to extinction occurred in the groups stimulated at 6.8 and $9.3 \mathrm{~Hz}$. But given the null effect obtained in the present experiment with $8.3-\mathrm{Hz}$ stimulation, we cannot place too much weight on these negative results. They do, however, support the view that stimulation at $7.5 \mathrm{~Hz}$ has special effects in comparison with other frequencies.

\section{EXPERIMENT 3}

The results of Experiments 1 and 2, above, combined with previous findings (Glazer, 1974a, 1974b; Gray, 1972; Holt, 1982; Holt \& Gray, 1983b, 1985), indicate that theta-driving stimulation has long-term nonassociative frequency-specific behavioral functions. Motor, memory, and mapping theories of theta cannot account for these results, but they are broadly consistent with Gray's $(1970,1982)$ frustration-anxiety hypothesis of theta function. However, the long-term nonassociative effects of theta-frequency stimulation could, in principle, result from stable non-theta neurophysiological changes, such as altered LTP (Staubli \& Lynch, 1987), rather than from changes in frustration. In Experiment 3, we tested this possibility by comparing the effects on extinction of applying theta driving before or after acquisition of the FR5 response. If theta driving exerts its behavioral effects via stable long-term nonassociative neurophysiological changes uninvolved in theta, it should have similar effects on extinction if applied before or after FR5 acquisition. On the other hand, if theta subserves anxiety (as predicted by Gray, 1970, 1982), the particular properties of the FR5 paradigm (Williams et al., 1990; Williams et al., 1989) mean that theta driving applied before or after acquisition of the FR5 response should have opposite effects on its resistance to extinction, as explained in more detail below.

Gray's $(1970,1982)$ frustration-anxiety hypothesis of theta function proposed that 7.7-Hz (Gray \& Ball, 1970) or $8.3-\mathrm{Hz}$ theta driving mimics the central effects of frustrative nonreward. This induces tolerance to nonreward via generalized counterconditioning (Amsel, 1972, 1992; Chen \& Amsel, 1977, 1982). Williams et al. (1990) have shown that the FR5 paradigm may be equivalent to a discrete-trial PRF schedule, with the first four responses of each FR5 chain constituting nonrewarded trials. Therefore, the animals encounter nonreward during the acquisition of the FR5 response. Under these circumstances, theoretical expectations for the behavior of animals rendered tolerant to nonreward become complex.

One possible account is that theta-driving stimulation applied before acquisition would induce tolerance for nonreward in a manner equivalent to that caused by anxiolytic drugs administered during acquisition (Gray, 1977). Anxiolytics induce tolerance for nonreward and so reduce or abolish the partial reinforcement extinction effect (PREE) (Feldon, Guillamon, Gray, De Wit, \& McNaughton, 1979; Feldon \& Gray, 1981) (since the PREE depends in part on the counterconditioning of conditioned frustration during acquisition-Amsel, 1962, 1992). Thus animals rendered tolerant to nonreward by theta-driving stimulation applied prior to acquisition of the FR5 response (equivalent to a PRF schedule) should show a smaller PREE--that is, reduced resistance to extinction of this response relative to unstimulated controls. This is the effect obtained in Experiment 2 with $7.5-\mathrm{Hz}$ stimulation. Thus, given the resemblance between FR5 and PRF schedules (Williams et al., 1990), we must now interpret $7.5-\mathrm{Hz}$ stimulation as inducing tolerance for nonreward. Conversely, the same logic now leads us to propose that $8.3-$ or $7.7-\mathrm{Hz}$ theta driving sensitizes animals to nonreward. Consequently, during FR5 acquisition, the nonrewarded responses (one to four) of the FR5 chain would cause more conditioned frustration, leading to greater counterconditioning and so finally to the observed increase in resistance to extinction (equivalent to a greater PREE).

If this new analysis is correct, then applying $8.3-\mathrm{Hz}$ stimulation between acquisition and extinction should 


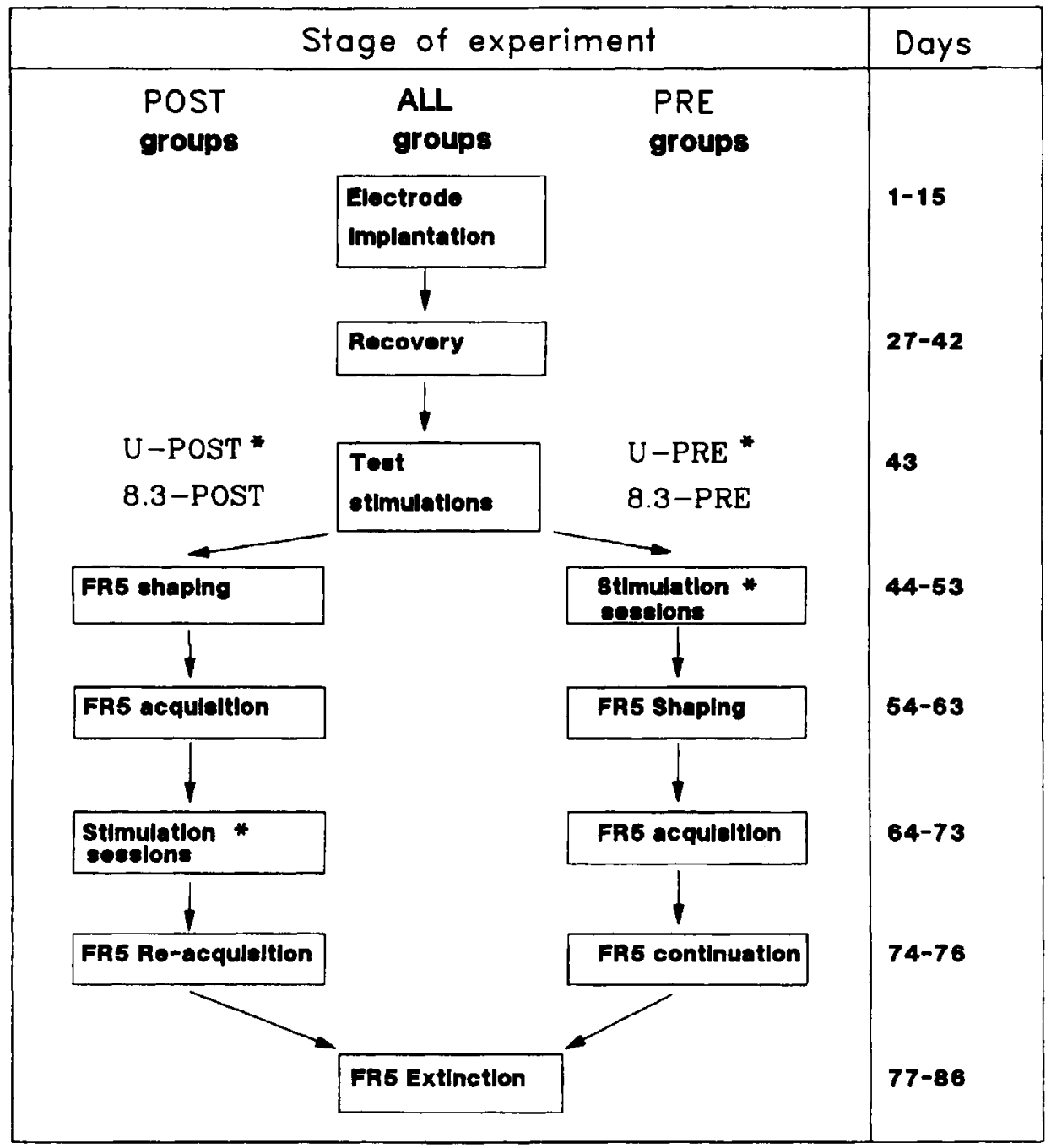

Figure 5. A diagrammatic representation of the design of Experiment 3. All rats received electrode implants and test stimulations before allocation to experimental groups. The U-PRE and 8.3-PRE groups were run in stimulation sessions before FR5 shaping and acquisition training, whereas the U-POST and 8.3-POST groups received FR5 shaping and acquisition training before stimulation sessions. Finally, the PRE and POST groups were tested in FR5 extinction in tandem. The timing of each stage of the experiment for all groups is shown at the right of the diagram. *The U-PRE and U-POST groups were connected to the apparatus in each stimulation session, but no stimulating current was applied.

reverse its effects on resistance to extinction. For now, the assumption that the first poststimulation encounter with nonreward occurs during extinction of the FR5 response would be correct. Therefore, a rat sensitized to nonreward (i.e., one stimulated at 7.7 or $8.3 \mathrm{~Hz}$ ) would show decreased resistance to extinction. In Experiment 3, we tested this hypothesis. We predicted that, applied before acquisition, $8.3-\mathrm{Hz}$ stimulation would increase resistance to extinction but that, applied between acquisition and extinction, it would decrease resistance to extinction.

\section{Method}

The U-PRE and 8.3-PRE groups described below were common to this study and to Experiment 1, above.
Test stimulation showed theta driving in $41 / 45$ animals. Two rats had faulty recording connections, and 2 had threshold currents higher than $250 \mu \mathrm{A}$. These 4 rats were allocated to the two (see below) unstimulated control groups. The remaining rats were semirandomly allocated to five groups of 9: (1) unstimulated preacquisition (UPRE); (2) unstimulated postacquisition (U-POST); (3) $8.3 \mathrm{~Hz}$ stimulated preacquisition (8.3-PRE); (4) $8.3 \mathrm{~Hz}$ stimulated postacquisition (8.3-POST); (5) $7.7 \mathrm{~Hz}$ stimulated preacquisition. In this section, we are not concerned with the $7.7-\mathrm{Hz}$ stimulated group (see Experiment 1).

Figure 5 shows the experimental design. All the rats were run in 10 daily stimulation sessions. Rats in the U-PRE and 8.3-PRE groups were run in stimulation sessions on the 10 days immediately after the test session. Rats in the U-POST and 8.3-POST groups were shaped to the FR5 response during this time. For the next 10 days, rats in the POST groups received daily sessions of 
FR5 acquisition training, and rats in the PRE groups were shaped to the FR5 response. Subsequently, the PRE groups received 10 days of FRS acquisition while the POST groups were run in 10 stimulation sessions. Finally, all groups received a further 3 days of FR5 acquisition training and 10 days of extinction testing in tandem.

Two animals did not acquire the FR5 response. The final group sizes were as follows: nine U-PRE, nine 8.3-PRE, eight U-POST, and eight 8.3-POST. The log-transformed latency data were analyzed in three-factor ANOVAs: stimulation (unstimulated vs. $8.3 \mathrm{~Hz}$ stimulated) $\times$ timing (PRE- or POST-acquisition stimulation) $\times$ days (of acquisition training or extinction testing).

\section{Results}

Theta-driving measures. The mean theta-driving thresholds of the experimental and control groups were as follows: 8.3-PRE, $129 \mu \mathrm{A}$; U-PRE, $168 \mu \mathrm{A}$; 8.3POST, $150 \mu \mathrm{A}$; U-POST, $161 \mu \mathrm{A}$. These values did not differ significantly $(F<1)$. The mean frequencies of driven theta were $8.28 \pm 0.15 \mathrm{~Hz}$ for the 8.3-PRE group and $8.40 \pm 0.16 \mathrm{~Hz}$ for the 8.3 -POST group. These values did not differ significantly $(F<1)$. Figure 1 shows examples of driven theta.

Acquisition. All groups acquired the FR5 response, as indicated by a significant linear trend over days [total FR5 latency: $F(1,360)=24.3, p<.001]$. An ANOVA of the total FR5 latencies showed no significant differences between the stimulated and control groups during FR5 acquisition training or during the last 3 days of FR5 acquisition/reacquisition (all $F \mathrm{~s}<1$; data not shown).

Extinction. The 8.3-POST group showed faster extinction than did the U-POST group, but (as already re- ported in Experiment 1) the 8.3-PRE group was resistant to extinction in comparison with the U-PRE group (Figure 6). An ANOVA of the total FR5 latencies showed significant differences between the linear trends in the stimulation $\times$ timing $\times$ days interaction $[F(1,288)=4.21$, $p<.05]$. This effect was most marked for the $\mathrm{L}(2+3)$ scores $[F(1,288)=7.03, p<.01]$ (Figure 6). Post hoc comparisons between the linear coefficients confirmed that 8.3-POST rats extinguished more quickly than U-POST controls $[t(288)=2.16, p<.05]$, whereas 8.3-PRE rats were significantly resistant to extinction in comparison with U-PRE controls $[t(288)=2.35, p<.05]$.

\section{Discussion}

8.3-Hz theta-driving stimulation applied after FR5 acquisition reduced subsequent resistance to extinction, but the same stimulation applied before FR5 acquisition increased resistance to extinction. These results are in line with Gray's $(1970,1982)$ frustration-anxiety hypothesis of theta function. Long-term nonassociative effects of septal stimulation on neurophysiological processes such as LTP cannot readily explain the opposite effects of pre- and postacquisition theta-driving stimulation on resistance to extinction. Therefore, these results support our revised hypothesis (see introduction) that $8.3-\mathrm{Hz}$ theta driving proactively increases sensitivity to conditioned frustrative stimuli.

To recapitulate our revised analysis, rats stimulated at $8.3 \mathrm{~Hz}$ after FR5 acquisition are more sensitive to conditioned frustrative stimuli during extinction, when as-

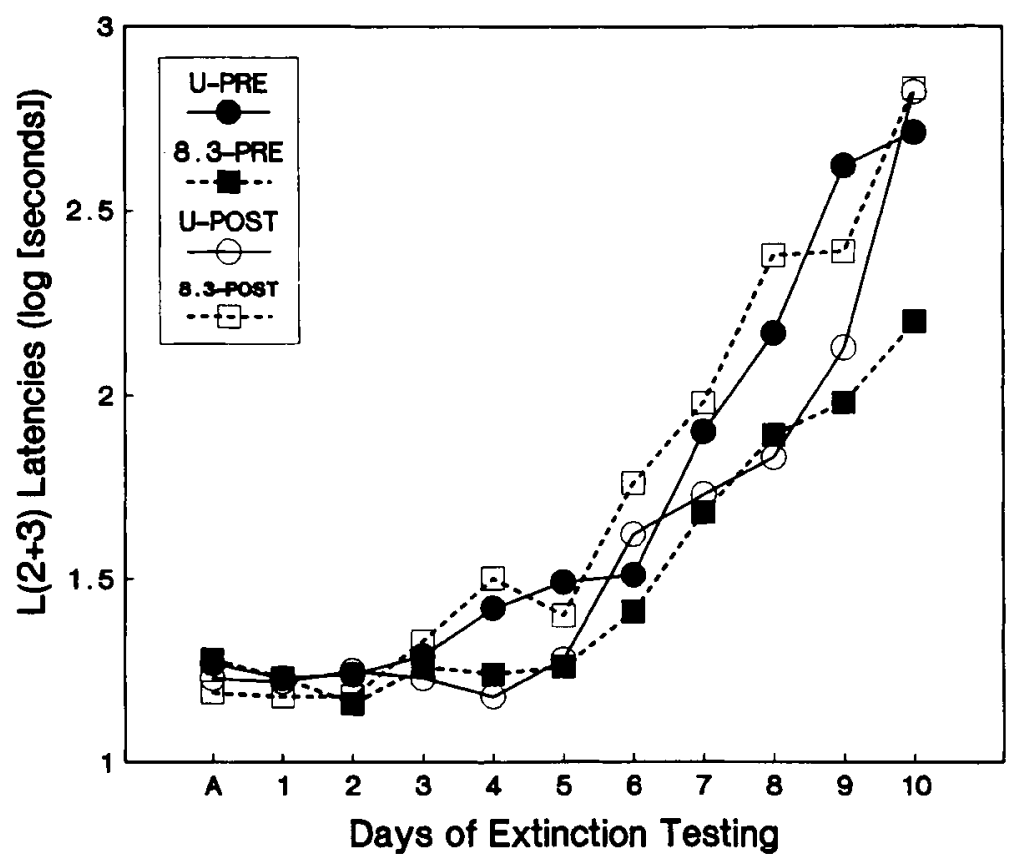

Figure 6. The $L(2+3)$ scores of the PRE- and POST-acquisition stimulated (8.3-PRE, 8.3-POST) and control (U-PRE, U-POST) groups (ordinate) on the last day of acquisition (A) and the 10 days of extinction (abscissa). The values shown are the means of logtransformed data. 
sociative counterconditioning cannot occur. Thus, on the hypothesis set out here, the intensity of their conditioned frustration, and therefore their rate of extinction, is greater than in unstimulated controls. In contrast, the group stimulated before FR5 acquisition is initially more sensitive to conditioned frustrative stimuli due to nonassociative mechanisms (since no such stimuli have yet occurred). Since the FR5 paradigm appears equivalent to an alley PRF schedule, it elicits conditioned frustration which (1) undergoes greater counterconditioning during FR5 acquisition (see Amsel, 1962, 1972, 1992) so that (2) the rats show ultimately more resistance to extinction of FR5 responding.

The logic of our revised analysis (see above) suggests that theta driving could alter the initial stages of conditioning by increasing initial frustration and counterconditioning. In PRF runway experiments, the counterconditioning during acquisition can sometimes give rise to faster responding (see Amsel, 1992). However, this partial reinforcement acquisition effect (PRAE) is usually small or absent, in contrast to the large and robust PREE. The present studies did not observe any change in FR5 acquisition due to theta-driving stimulation. It is possible that theta driving caused a PRAE during shaping of the FR5 response, but in the present experiment FR5 latencies were not collected during shaping. Further studies are needed in order to analyze whether theta driving alters early acquisition of operant responding.

Since the FR5 paradigm appears to be equivalent to a runway PRF schedule (Williams et al., 1990; Williams et al., 1989), the interpretation of the present findings is the opposite of that proposed by Holt and Gray (1983b, 1985 ). Holt and Gray suggested that $7.7-\mathrm{Hz}$ (actually $8.3-\mathrm{Hz}$ ) theta driving reduced sensitivity to conditioned frustrative stimuli. But the present finding that postacquisition $8.3-\mathrm{Hz}$ theta driving facilitated extinction clearly indicates that the stimulation increases sensitivity to such stimuli. Holt and Gray (1983b) also suggested that preacquisition theta-driving stimulation directly increased resistance to extinction. They did not exclude the possibility that the increased resistance to extinction could result from alterations in acquisition processes. However, the present finding that pre- and postacquisition stimulation had opposite effects on extinction indicates that the effects of preacquisition theta-driving septal stimulation on extinction are indeed mediated by changes in acquisition processes (though, as shown in Experiments 1 and 2, they are not merely secondary to changed acquisition performance).

At first sight, the present finding that postacquisition $8.3-\mathrm{Hz}$ theta driving reduced resistance to extinction of FR5 responding conflicts with Glazer's (1974a) results. Glazer increased $7.5-$ to $8.5-\mathrm{Hz}$ theta between acquisition and extinction of the FR5 response by instrumentally rewarding theta production. In contrast to the present findings, he found that increasing theta by this procedure increased resistance to extinction. The apparent discrepancy between Glazer's (1974a) results and the present findings is explained simply by the fact that he counterconditioned theta by the immediate delivery of food. In contrast, in the present study, we avoided pairing theta driving with reward, so that the anxiogenic effects of theta driving were not absorbed by counterconditioning and persisted to facilitate FR5 extinction. However, the designs of both Glazer's (1974a) and the present study are open to interpretation under Landfield's (1977) memory consolidation hypothesis of theta function. To avoid this objection, it is important to test our new hypothesis relating theta frequencies to anxiety in a different paradigm. We have now done this (Snape et al., 1996; see General Discussion, below), with results that essentially confirm our revised hypothesis that $7.7-\mathrm{Hz}$ theta driving sensitizes animals to nonreward.

In summary, $8.3-\mathrm{Hz}$ theta-driving stimulation sensitizes rats to conditioned frustrative stimuli proactively via nonassociative mechanisms. The effects of this sensitization on resistance to extinction are mediated by associative processes involving the conditioned frustrative stimuli first encountered.

\section{GENERAL DISCUSSION}

The present results are consistent with our earlier reports using the same basic paradigm (Holt, 1982; Holt \& Gray, 1983a, 1983b; Williams, 1988; Williams et al., 1990; Williams et al., 1989). Together, these results indicate that theta elicited by septal stimulation has longterm nonassociative effects on behavior that are exquisitely frequency-specific. To be precise, (1) applied prior to FR5 acquisition, theta-driving stimulation at 7.7 or $8.3 \mathrm{~Hz}$ increased resistance to extinction of this response (Experiment 1); (2) applied prior to FR5 acquisition, theta-driving stimulation at $7.5 \mathrm{~Hz}$ decreased resistance to extinction of this response (Experiment 2); (3) the effect of $8.3-\mathrm{Hz}$ stimulation was not observed when other rats were stimulated at $7.5 \mathrm{~Hz}$ in the same experiment (Experiment 2); (4) applied between acquisition and extinction, theta-driving stimulation at $8.3 \mathrm{~Hz}$ decreased resistance to extinction of the FR5 response (Experiment 3 ). Results 1 and 2 indicate that theta is not merely an epiphenomenon of motor activity, but can alter behavior. Results 1, 2, and 4 are consistent with a revised version of Gray's $(1970,1982)$ frustration-anxiety hypothesis of theta function. Further data consistent with Results 1, 2, and 4 are reported by Snape et al. (1996; Snape, 1991; see below). Result 3 does not find explanation within this model; the cause of this robust pattern of results is uncertain.

In the present study, $7.5-\mathrm{Hz}$ and $7.7-$ or $8.3-\mathrm{Hz}$ thetadriving septal stimulation had opposite effects on behavior. These results are broadly consistent with the findings of previous studies, in which theta was induced pharmacologically or instrumentally (Bohus et al., 1978; de Wied et al., 1978; Glazer, 1972, 1974a; Urban \& de Wied, 1978). Together, the present and previous findings strongly indicate that theta is not merely an epiphenomenon of motor activity; it can alter behavior. The striking contrast between the behavioral effects of $7.5-$ and $7.7-\mathrm{Hz}$ 
theta driving is completely novel. In most studies in which theta was related to the power spectrum of the electroencephalogram, its dominant frequencies were not even differentiated at this high level of resolution. The intra- and interspecific generality of the present observations should be analyzed in further experiments.

Snape et al. (1996) have also observed opposite effects of 7.5 - and $7.7-\mathrm{Hz}$ preacquisition theta driving in the alley (see below). These results reinforce the view that these adjacent theta frequencies have exquisitely specific effects on behavior. The present findings complement the observations of Snape et al. by showing that these frequency-specific effects of theta driving are independent of the spatial qualities of the test paradigm. Furthermore, the use of preacquisition theta driving in both Snape's and the present studies precludes interpretation of their results under memorial hypotheses of theta function, since the animals had no experience of the test paradigms prior to stimulation. Hence the present results indicate that $7.5-$ and $7.7-\mathrm{Hz}$ theta are specifically and differentially related to behavior independently of theta's proposed roles in spatial mapping (O'Keefe, 1993; O’Keefe \& Nadel, 1978) or memory (Landfield, 1977; Larson et al., 1986; Larson et al., 1993).

The opposite behavioral effects of theta driving at $7.5 \mathrm{~Hz}$ or $7.7-8.3 \mathrm{~Hz}$ in the present studies were nonassociative and expressed over long time periods (weeks). The nature of these behavioral effects is consistent with their roles in frustration and anxiety, broadly as predicted by Gray (1970, 1982; see below). But the neural mechanisms by which specific theta frequencies may modulate anxiety are uncertain. To the best of our knowledge, no theta-driving studies have looked for opposite neurophysiological effects of frequencies as close as 7.5 and $7.7 \mathrm{~Hz}$. Correlational work has shown that the associations between the synaptic functions of hippocampal pyramidal cells and theta power reverse over theta frequencies between 7 and $8 \mathrm{~Hz}$ in mice (Jeantet \& Jaffard, 1981). One plausible neurochemical mechanism that may account for the proactive behavioral effects of theta driving is an increase in hippocampal noradrenergic function, as discussed in our companion paper (Snape et al., 1996). Further studies using septal stimulation to manipulate theta are needed in order to confirm the frequency specificity of theta's behavioral roles, reported here, and to elucidate its neurophysiological basis.

The opposite behavioral effects of pre- and postacquisition theta driving are consistent with the frustrationanxiety hypothesis of theta function. However, the present studies cannot completely exclude the possibility that the theta frequency septal stimulation altered behavior by interfering with non-theta processes, such as altered LTP (e.g., Larson et al., 1993; Staubli \& Lynch, 1987). To do so, it would be necessary to show that eliminating the effects of septal stimulation on theta, while preserving all its other neurophysiological actions, prevented the behavioral changes reported here. Existing methods of achieving this elimination (e.g., section of the fimbria-fornix; Rawlins et al., 1980b) themselves af- fect resistance to extinction (e.g., Rawlins, Feldon, \& Gray, 1980a; Williams et al., 1990). Therefore, comparison between closely adjacent frequencies of thetadriving septal stimulation probably provides the best available control for the possibility that theta-driving stimulation altered behavior by interfering with neural systems uninvolved in theta production.

A possible artifact in our experiments is that animals with faulty electrode connections $(n=11)$ or poor theta driving ( $n=3$ ) were allocated to the unstimulated control groups. The rats with faulty connections had their electrodes located in the medial septum, but the connections broke after implantation while the wires were being led to the Amphenol sockets. However, the latter 3 rats may have had electrodes located at sites different from those in the animals with good theta driving (though histological analysis failed to disclose any such differences; Williams, 1988). It is possible that consequent differences in the damage resulting from electrode implantation might have influenced behavior. But this possible artifact is unlikely to have biased our results, for two reasons. First, it could not have given rise to different directions of behavioral change at different stimulation frequencies ( 7.5 vs 7.7 and $8.3 \mathrm{~Hz}$ ) or timing (before vs. after acquisition). Second, Snape et al. (1996) allocated rats to unstimulated groups randomly within good theta drivers and obtained results consistent with those reported here.

The present findings broadly support Gray's (1970, 1982) hypothesis that the functions of theta undergo a transition at frequencies close to $7.7 \mathrm{~Hz}$. The frequency specificities for theta function which Gray postulated parallel those observed here closely, but not precisely. This necessitates some revision of the hypothesis (see Experiment 3, Discussion). Snape et al. (1996; see also Snape, 1991, and Williams et al., 1989) have obtained support for the revised model of the frustration-anxiety hypothesis of theta function developed here. They studied the effects of preacquisition $7.5-$ or $7.7-\mathrm{Hz}$ thetadriving stimulation (which Experiment 1, above, showed was functionally equivalent to $8.3 \mathrm{~Hz}$ ) in the runway. Rats stimulated at $7.7 \mathrm{~Hz}$ before CRF acquisition training extinguished more quickly than CRF-trained unstimulated controls. This supports our proposal that $7.7-\mathrm{Hz}$ theta driving proactively increases sensitivity to conditioned frustrative stimuli via a nonassociative process. In addition, PRF-trained $7.7-\mathrm{Hz}$ stimulated animals were more resistant to extinction than PRF-trained unstimulated controls. This indicates that $7.7-\mathrm{Hz}$ theta driving enhances the associative counterconditioning of conditioned frustrative stimuli resulting from nonreward during PRF acquisition in the alley. These results strongly support the view that $7.7-\mathrm{Hz}$ theta-driving stimulation can increase sensitivity to conditioned frustrative stimuli by means of a nonassociative process, and that this increases subsequent associative counterconditioning of such stimuli. Conversely, $7.5-\mathrm{Hz}$ theta-driving stimulation applied prior to acquisition of a running response increased resistance to extinction in animals subsequently trained on CRF and decreased it in animals trained on PRF (a re- 
duction in the PREE). By analogy with the reasoning presented above for $7.7-\mathrm{Hz}$ stimulation, these results both indicate that $7.5-\mathrm{Hz}$ theta driving increases tolerance for nonreward and strongly support the present model.

In summary, the present results show that theta-driving septal stimulation has long-term nonassociative effects on behavior. These behavioral effects depend on the frequency and timing of the stimulation in ways which indicate that they result from driving theta. The present results cannot be explained by motor, memory, or mapping hypotheses, but are consistent with a revised version of Gray's $(1970,1982)$ frustration-anxiety hypothesis of theta function. This hypothesis is part of a larger theory of the neuropsychology of anxiety which attempts to explain clinical phenomena in man. Analogies between rodent theta and human EEG rhythms have yet to be established. However, one study (Hare, Timmins, Roberts, \& Burman, 1982) has shown that altering the EEG can modulate anxiety in man. In this study, biofeedback which enhanced alpha production reduced symptoms in $50 \%$ of patients with chronic anxiety that had resisted all other treatments. Further analyses of frequency-specific EEG manipulations may be able to increase our understanding of anxiety and so help to improve its treatment.

\section{REFERENCES}

AMSEL, A. (1962). Frustrative nonreward in partial reinforcement and discrimination learning: Some recent history and a theoretical extension. Psychological Review, 69, 306-328.

AMSEL, A. (1972). Behavioral habituation, counter-conditioning and a general theory of persistence. In A. H. Black \& W. F. Prokasy (Eds.), Classical conditioning II: Current research and theory (pp. 409426). New York: Appleton-Century-Crofts.

Amsel, A. (1992). Frustration theory. New York: Cambridge University Press.

azmitia, E. C., McNaughton, N., Tsaltas, L., Fillenz, M., \& Gray, J. A. (1985). Interactions between hippocampal serotonin and the pituitary-adrenal axis in the septal driving of hippocampal theta rhythm. Neuroendocrinology, 39, 471-475.

BLAND, B. H. (1986). The physiology and pharmacology of the hippocampal theta rhythms. Progress in Neurobiology, 26, 1-54.

Bohus, B., Urban, I., van Greidanus, T. B. W., \& DE Wied, D. (1978). Opposite effects of oxytocin and vasopressin on avoidance behavior and hippocampal theta rhythm in the rat. Neuropharmacology, 17, 239-247.

Buszaki, G., Rappelsberger, P., \& Kellenyi, L. (1985). Depth profiles of hippocampal rhythmic slow activity ("theta rhythm") depend on behavior. Electroencephalography \& Clinical Neurophysiology, 61, 77-88.

Chen, J.-S., \& Amsel, A. (1977). Prolonged, unsignaled, inescapable shocks increase persistence in subsequent appetitive instrumental learning. Animal Learning \& Behavior, 5, 377-385.

Chen, J.-S., \& Amsel, A. (1982). Habituation to shock in preweanling, juvenile and adult rats. Journal of Experimental Psychology: Animal Behavior Processes, 8, 113-120.

Deupree, D., Coppock, W., \& Willer, H. (1982). Pretraining septal driving of hippocampal rhythmic slow activity facilitates acquisition of visual discrimination. Journal of Comparative \& Physiological Psychology, 96, 557-562.

DE WIED, D., Bohus, B., van ReE, J. M., \& Urban, I. (1978). Behavioral and electrophysiological effects of peptides related to lipotropin ( $\beta$-LPH). Journal of Pharmacology \& Experimental Therapeutics, 204, 570-580.
Feldon, J., \& Gray, J. A. (1981). The partial reinforcement extinction effect after treatment with chlordiazepoxide. Psychopharmacology, 73, 269-275.

Feldon, J., Gulllamon, A., Gray, J. A., De Wit, H., \& McNaughton, N. (1979). Sodium amylobarbitone and responses to nonreward. Quarterly Journal of Experimental Psychology, 31, 19-50.

GLAZER, H. I. (1972). Physostigmine and resistance to extinction. Psychopharmacology, 26, 387-394.

GLAZER, H. I. (1974a). Instrumental conditioning of hippocampal theta and subsequent response persistence. Journal of Comparative \& Physiological Psychology, 86, 267-273.

GLAZER, H. I. (1974b). Instrumental response persistence following induction of hippocampal theta frequency during fixed-ratio responding in rats. Journal of Comparative \& Physiological Psychology, 86, 1156-1162.

Graham-Jones, S., Holt, L., Gray, J. A., \& Fillenz, M. (1985). Lowfrequency septal stimulation increases tyrosine hydroxylase activity in the hippocampus. Pharmacology, Biochemistry \& Behavior, 23, 489-494.

GRAY, J. A. (1970). Sodium amobarbital, the hippocampal theta rhythm and the partial reinforcement extinction effect. Psychological Review, 77, 465-480.

Gray, J. A. (1972). Effects of septal driving of the hippocampal theta rhythm on resistance to extinction. Physiology \& Behavior, 8, 481-490.

Gray, J. A. (1977). Drug effects on fear and frustration: Possible limbic site of action of minor tranquillizers. In L. L. Iversen, S. D. Iversen, \& S. H. Snyder (Eds.), Handbook of psychopharmacology: Vol. 8. Drugs, neurotransmitters and behavior (pp. 433-529). New York: Plenum.

Gray, J. A. (1982). The neuropsychology of anxiety: An enquiry into the functions of the septo-hippocampal system. Oxford: Oxford University Press.

Gray, J. A., \& Ball, G. G. (1970, June 5). Frequency-specific relation between hippocampal theta rhythm, behavior and amobarital action. Science, 168, 1246-1248.

Gray, J. A., McNaughton, N., James, D. T. D., \& Kelly, P. H. (1975). Effect of minor tranquillisers on hippocampal theta rhythm mimicked by depletion of forebrain noradrenaline. Nature, 258, 424-425.

Green, J. D., \& Arduini, A. R. (1954). Hippocampal electrical activity in arousal. Journal of Neurophysiology, 17, 553-557.

Hare, J. F., Timmins, B. H., Roberts, J. R., \& Burman, A. S. (1982). EEG alpha biofeedback training: An experimental technique for the management of anxiety. Journal of Medical Engineering Technology, 6, 19-24.

HoLr, L. (1982). Proactive behavioral effects of septal stimulation in the rat. Unpublished doctoral dissertation, Oxford University.

Holt, L., \& GRAY, J. A. (1983a). Proactive behavioral effects of thetablocking septal stimulation in the rat. Behavioral \& Neural Biology, 39, 7-21.

Holt, L., \& Gray, J. A. (1983b). Septal driving of the hippocampal theta rhythm produces a long-term, proactive and non-associative increase in resistance to extinction. Quarterly Journal of Experimental Psychology, 35B, 97-118.

Holt, L., \& GRAY, J. A. (1985). Proactive behavioral effects of thetadriving septal stimulation on conditioned suppression and punishment in the rat. Behavioral Neuroscience, 99, 60-74.

James, D. T. D., McNaughton, N., Rawlins, J. N. P., Feldon, J., \& GRAY, J. A. (1977). Septal driving of hippocampal theta rhythm as a function of frequency in the free-moving male rat. Neuroscience, 2 , $1007-1017$.

JeAnteT, Y., \& JAFFard, R. (1981). Relations quantitatives entre la densité spectrale de l'activité biolélectrique spontanée et l'excitabilité des synapses commissurales du champ CAl de l'hippocampe dorsal chez la Souris éveillée. Comptes Rendues de l'Acadamie de Sciences de Paris, 293 (Série III), 545-548.

Kramis, W. R., \& Vanderwolf, C. H. (1980). Frequency-specific RSA-like hippocampal patterns elicited by septal, hypothalamic and brain stem electrical stimulation. Brain Research, 192, 383-398.

LANDFIELD, P. W. (1977). Different effects of post-trial driving or blocking of the theta rhythm on avoidance learning in rats. Physiology \& Behavior, 18, 439-445. 
LARSON, J., \& LYNCH, G. (1986, May 23). Induction of synaptic potentiation in hippocampus by patterned stimulation involves two events. Science, 232, 985-988.

LARSON, J., WANG, L., \& LyNCH, G. (1986). Patterned stimulation at theta frequency is optimal for the induction of hippocampal longterm potentiation. Brain Research, 368, 347-350.

LaRson, J., XiaO, P., \& LyNCH, G. (1993). Reversal of LTP by theta frequency stimulation. Brain Research, 600, 97-102.

LEUNG, L.-W. S. (1984). Theta thythm during REM sleep and waking: Correlations between power phase and frequency. Electroencephalography \& Clinical Neurophysiology, 58, 553-564.

LynCh, G., Kessler, M., Arai, A., \& Larson, J. (1990). The nature and causes of hippocampal long-term potentiation. Progress in Brain Research, 83, 233-250.

McNaughton, N., Azmitia, E. C., Williams, J. H., Buchan, A. M., \& GraY, J. A. (1980). Septal elicitation of hippocampal theta rhythm after localized de-afferentation of serotoninergic fibres. Brain Research, 200, 259-269.

McNaughton, N., James, D. T. D., Stewart, J., Gray, J. A., Valero, I., \& Drewnowski, A. (1977). Septal driving of hippocampal theta rhythm as a function of frequency in the male rat: Effects of drugs. Neuroscience, 2, 1019-1027

Morris, R. G. M., \& Hagan, J. J. (1983). Hippocampal electrical activity and ballistic movement. In W. Seifert (Ed.), Neurobiology of the hippocampus (pp. 321-331). New York: Academic Press.

O'KEEFE, J. (1993). Hippocampus, theta and spatial memory. Current Opinion in Neurobiology, 30, 917-924.

O'KeEFE, J., \& NADEL, L. (1978). The hippocampus as a cognitive map. Oxford: Oxford University Press, Clarendon Press.

Rawlins, J. N. P., Feldon, J., \& Gray, J. A. (1980a). The effects of hippocampectomy and of fimbria section upon the partial reinforcement extinction effect in rats. Experimental Brain Research, 38, 273-283.

Rawlins, J. N. P., Feldon, J., \& Gray, J. A. (1980b). Septo-hippocampal connections and the hippocampal theta rhythm. Experimental Brain Research, 37, 49-63.

SNAPE, M. (1991). An investigation of the effects of proactive theta driving septal stimulation on tolerance for stress. Unpublished doctoral dissertation, University of London.

Snape, M., Grigoryan, G., Sinden, J. D., \& Gray, J. A. (1996). Dependence of the proactive behavioral effects of theta-driving septal stimulation on stimulation frequency and behavioral experience:
2. Continuously and partially reinforced running. Psychobiology, 24, 22-32.

Staubli, U., \& Lynch, G. (1987). Stable hippocampal long-term potentiation elicited by "theta" pattern stimulation. Brain Research, 435, 227-234.

STEWART, M., \& Fox, S. E. (1991). Hippocampal theta activity in monkeys. Brain Research, 538, 59-63.

STUMPF, C. (1965). Drug action on the electrical activity of the hippocampus. International Review of Neurobiology, 8, 77-138.

URBAN, I., \& DE WIED, D. (1978). Neuropeptides: Effects on paradoxical sleep and theta rhythm in rats. Pharmacology, Biochemistry \& Behavior, 8, 51-59.

VANDERWOLF, C. H. (1971). Limbic-diencephalic mechanisms of voluntary movement. Psychological Review, 78, 83-113.

VERTES, R. P. (1986). Brain stem modulation of the hippocampus: anatomy, physiology and significance. In R. L. Isaacson \& K. H. Pribram (Eds.), The hippocampus (Vol. 4, pp. 41-75). New York: Plenum.

Wetzel, W., OtT, T., \& Matthies, H. (1977). Post-training hippocampal rhythmic slow activity ("theta") elicited by medial septal stimulation improves memory consolidation in rats. Behavioral Biology, 21, 32-40.

Whishaw, I. Q., \& VANDERWolf, C. H. (1973). Hippocampal EEG and behavior: Changes in amplitude and frequency of RSA (theta rhythm) associated with spontaneous and learned movement patterns in rats and cats. Behavioral Biology, 8, 461-484.

Williams, J. H. (1988). An investigation of long-term pro-active nonassociative mechanisms by which theta-driving septal stimulation alters behaviour in rats. Unpublished doctoral dissertation, Oxford University.

Williams, J. H., Gray, J. A., Sinden, J. D., Buckland, C., \& RawlINS, J. N. P. (1990). Effects of GABAergic drugs, fornicotomy, hippocampectomy and septal lesions on the extinction of a discretetrial fixed ratio 5 lever-press response. Behavioral Brain Research, 41, 129-150.

Williams, J. H., Gray, J. A., Snape, M., \& Holt, L. (1989). Long-term effects of septo-hippocampal stimulation on behavioural responses to anxiogenic stimuli. In P. Tyrer (Ed.), Psychopharmacology of anxiety (British Association for Psychopharmacology Monograph No. 11, pp. 80-108). Oxford: Oxford University Press.

(Manuscript received March 21, 1995; revision accepted for publication July 5,1995 .) 